\title{
MUJERES RELIGIOSAS: BEATAS Y BEGUINAS EN LA EDAD MEDIA. TEXTOS SATÍRICOS Y MISÓGINOS ${ }^{1}$
}

\author{
Pedro SAntonja
}

\begin{abstract}
Resumen: Algunas mujeres para tratar de escapar de la presión familiar y social que se ejercía por parte de la sociedad medieval buscaron formar parte de la esfera religiosa integrándose en conventos y monasterios. Las beatas y beguinas tendrán una consideración negativa en la literatura hispánica y europea medieval como se refleja en este trabajo a través de la descripción y análisis de diferentes pasajes y obras literarias.
\end{abstract}

Palabras claves: monjas, beatas, beguinas, misoginia, literatura satírica, Edad Media.

\begin{abstract}
Some women, to try to escape from the family and social pressure which was exerted by the medieval society, looked for being part of the religious circles integrating with convents and monasteries. The beatified and pious women will have a negative consideration in the hispanic and medieval european literature, as it is captured in this work through the description and analysis of different passages and literary works.
\end{abstract}

Keywords: nuns, beatified woman, pious woman, misoginy, satirical literature, Middle Age.

Los lugares y espacios propios de las mujeres en esta etapa histórica que estudiamos eran la casa, el palacio o castillo, el convento o monasterio y, en algunos casos, el prostíbulo. La presión social que sufrían las mujeres y su peculiar ámbito familiar invitaban a la huida y a la búsqueda del sosiego y quietud

\footnotetext{
1. Siglas: BAC: Biblioteca de Autores Cristianos, CNEC: Centre National d'Études Cathares, CSIC: Consejo Superior de Investigaciones Científicas, EF: Estudios Franciscanos, ENC: Els Nostres Clàssics, FUE: Fundación Universitaria Española.
} 
en el retiro del mundo, tal era el caso de muchas «beatas» ${ }^{2}$, que adoptaron una forma muy singular de vida santa fuera de los muros monásticos. Otras buscaron refugio en «beaterios» (béguinages) o en otros centros espirituales: conventos, monasterios y, excepcionalmente, ermitas rupestres (vida eremítica). También había otras mujeres religiosas que se encerraban entre cuatro paredes, a las que se les llamaba «mujeres emparedadas»: Llamavanse semejantes mugeres inclusas, reclusas, hermitañas o emparedadas, y se encerravan entre quatro paredes, no en castigo de su mal vivir, sino libre y voluntariamente y con la aprobación de sus confessores, $i$ assenso de sus parientes para hacer penitencia, entregarse a la contemplación, i para conseguir otros fines buenos ${ }^{3}$. Parece ser que, a diferencia de estos emparedamientos voluntarios, hubo otros forzados y penales, establecido para castigo más o menos riguroso según la gravedad de la culpa ${ }^{4}$.

2. La etimología de la palabra «beata, beato» (adjetivo, beata, beato, o sustantivo, el beato, la beata) equivale al adjetivo latino beatus, a, um, que, entre sus acepciones incluye las de feliz, dichoso, contento, afortunado, satisfecho, alegre... Deriva este adjetivo del verbo beo, as, are, que significa hacer feliz. Por este motivo, la legislación eclesiástica consideraba beatos a aquellos cristianos que habían merecido que Dios les hiciera felices, por lo que se consideraban oficialmente beatos a aquellos que se encuentran a un paso solamente de la canonización. Véase Palacios Alcalde, M., «Las beatas ante la Inquisición» en Hispania Sacra, Revista de Historia Eclesiástica de España, año 40, enero-junio, 1988, Centro de Estudios históricos. CSIC, Madrid, 1988, pp. 107-131, cita de las páginas 110-111.

3. TeIXIDOR, J., Antigüedades de Valencia, observaciones críticas donde con instrumentos auténticos se destruye lo destruye lo fabuloso, dejando en su debida estabilidad lo bien fundado. Las escribió en 1767, Fr. Josef Teixidor, 2 tomos, imprenta de Francisco Vives Mora, Valencia, 1895. Tomo II, p. 247.

4. Tratado histórico-apologético de las mugeres emparedadas; escrito a principios del s. xx por de Marco Antonio OrELLANA, y aumentado con algunas notas y aclaraciones en esta primera edición por Juan CHURAT y SAurí, Imprenta Casa de Beneficencia, Valencia, 1887. (Servicio de reproducción de libros, Colección Biblioteca Valenciana, Librerías «París-Valencia», Valencia, 1980, p. 9). La celda de emparedamiento que se conserva en Astorga es estrecha, oscura, como un sepulcro, y tiene tres vanos: dos son ventanas, una para comunicar con el exterior, la otra, hoy tapiada, estaba orientada hacia la cabecera de la parroquial de Santa Marta. La primera se usaba para el abastecimiento material; la segunda, para el espiritual, ya que le permitía seguir las funciones litúrgicas directamente desde la celda. El tercer vano es la puerta de acceso, tapiada durante la estancia de la emparedada en la celda, que hacía que la situación de emparedamiento fuera irreversible, ya que la puerta no volvía a abrirse hasta que la reclusa hubiese muerto; dicha puerta conduce a la celda desde el interior de la capilla de San Esteban. CAVEro DomínguEz, G., «Eremitismo y emparedamiento en la Edad Media (Diócesis de Astorga)» en Actas del Congreso sobre el monacato medieval en la diócesis de Astorga, Astorga, 1995, pp. 167-189. Cita de la página 185. En 1767 aún había dos emparedamientos en Bocairente (Valencia). Lo vio el P. Baltasar Calabuig, según atestigua Teixidor en Antigüedades de Valencia, Tomo II, p. 248: En este emparedamiento de Bocairente están aún dos emparedamientos enteros, que vio en este año 1767, el P. Fr. Bartholomé Calabuig, natural de la dicha villa, hijo de abito del convento de San Juan de Onteniente, que a ruego mío visitó y reconoció dicho antiguo emparedamiento; y el clérigo, que cuidaba de aquel santuario, le aseguró que él derribó otros catorce, i que los que estaban contiguos a la Iglesia sacavan a ella un agugero: de los quales quedan vestigios, como también del Comulgador torno y coro. En un Manual para entender y hablar el castellano que publicó en Valencia el P. Francisco Guijarro el año 1796, al fin del mismo insertó una colección de refranes entre los cuales se encuentra el siguiente: «Viuda lozana, o casada, o sepultada, o emparedada». Tratado histórico-apologético de las mujeres emparedadas, op. cit., p. 42. 
En España las «beatas» crecieron rápidamente. Estas mujeres hacían votos informales de castidad. Se declaraban exentas de pasiones sexuales y su actitud frente al matrimonio llegaba, en ocasiones, a los extremos de un rechazo total. Se dedicaban a las obras de caridad y a la piedad más estricta. En Italia, donde surgieron muchas de estas agrupaciones de mujeres en los siglos XIII, XIV y XV, a las participantes se les llamaba beguinas, mantellate, bizzocale (gazmoñas) o pinzochere (santurronas) $)^{5}$.

Con el paso del tiempo, y como veremos en ciertas composiciones literarias, el calificativo «beata» se empleó en tono despectivo o peyorativo. Se aplicaba a las que calentaban con exceso los bancos de las iglesias, a las que aparentaban ser extremadamente devotas, exagerando, algunas veces con cierta hipocresía, las prácticas del culto externo. Generalmente vestían de una forma muy parecida, que consistía en traer tocas blancas, saya parda, manto negro, cordón de San Francisco y andar sin chapines ${ }^{6}$. Este hábito, aunque fuese parecido al de los franciscanos, no hacía fraile a quien lo llevaba; se parecía más bien al hábito de los beguinos y beguinas, aludiendo claramente a otros grupos similares que tuvieron mucha importancia durante la Edad Media, sobre todo en la Europa del norte: Bélgica y Alemania ${ }^{7}$.

Tanto en la literatura de la Corona de Castilla como en la literatura de la Corona de Aragón encontramos referencias paródicas, de las beguinas (veguinas o bigardas), y de «beatas». Esta forma de caricaturesca de presentar a ciertas mujeres era resultado, sin duda, de una larga tradición misógina. Se tendía a ridiculizar de forma extrema aquellas actividades femeninas que rebasaban los límites que la sociedad les había establecido. En algunas obras literarias de la época el término «beguina» significaba «falsa beata», alcahueta, hechicera, tal como vemos en el Corbacho del Arcipreste de Talavera, en El conde Lucanor de Don Juan Manuel y en el Llibre de les dones o Spill de Jaume Roig.

En el Corbacho o reprobación del amor mundano ${ }^{8}$, el autor, Alfonso Martínez de Toledo, Arcipreste de Talavera, identifica a los beguinos, beguinas (vegui-

5. KIng, M., Mujeres renacentistas. La búsqueda de un espacio. Versión española de Aurora Lauzardo, ed. Alianza editorial. Madrid. 1992. pp. 141-142.

6. Véase: Relación de la información que se ha recibido contra Gaspar Lucas, prior de San Bartolomé de Jaén, demás de aquella con que fue preso, y que se le ha recibido contra sus beatas en general y contra alguna de ellas en particular. Y por su orden tomaban aquel estado y hábito que es no casarse, traer tocas blancas, saya parda, manto negro, cordón de San Francisco y andar sin chapines. Huerga, Á., Historia de los alumbrados. II. Los alumbrados de la Alta Andalucía (1575-1590). FUE. Seminario Cisneros. Madrid, 1978, p. 559. Chapín: Chanclo de corcho, forrado de cordobán, muy usado en algún tiempo por las mujeres.

7. Palacios Alcalde, M., Las beatas ante la Inquisición, op. cit. p. 112.

8. Constituye el Corbacho un tratado contra el pecado de la lujuria. Se ha considerado, con suma frecuencia, que el eje temático de esta obra es su invectiva contra las mujeres y que se emparenta con la tradición satírica 
nas) y bygardos (bagardos) con la falsa espiritualidad y con la hipocresía: Destos anda el mundo lleno, e con sus mansos hablares e dulces palabras, con sus disimuladas obras y sus juramentos rabiosos, dando a entender ser justos y muy santificados ${ }^{9}$. Dice a continuación el Arcipreste, sirviéndose de recursos técnicos propios del sermón popular: Yo creo bien que Nuestro Señor, pues los conoce bien, e pues él dijo que nos guardásemos dellos, guardémonos dellos, que estos falsos hipócritas son los que hacen los males insospechados... ${ }^{10}$. Acusa a estos hipócritas desbarbados malos de aprender artes mágicas: trabajan mucho por la virtudes de las yerbas por dar a las mujeres melecinas, a algunas para empreñar, a otras para sanar de la madre, del estómago, de la teta, del alfombra, de los paños a las preñadas, de la cara, el dolor del alaqueca, de hijada, del dolor del ombligo o desde abajo, etc ${ }^{11}$.

La misma repulsa y prevención muestra Jaume Roig por estas falsas devotas, beguinas y beatas, que el Arcipreste de Talavera y don Juan Manuel:

D’hipocresia/ e de parença/ haguí creença,/ tot son comport/

fos de coll tort,/ roseg altàs. Si no faltàs/ en profembria,/

queucon seria;/ mas avertint/ e inquirint/ de honestat,/gran malvestat/

la beateta/ sabia hac feta/ prou subtilment: / ella vilment/

se trobà prenys/ poc més o menys/ de uns tres meses;/

ab certes preses/ de diablures, / dos cristures/ es féu sortir/

e avortir/ secretament./Io'n fui felment/ certificat/

de son pecat ${ }^{12}$.

En este texto, el narrador ${ }^{13}$ nos introduce en un relato escabroso, de sátira agria, despiadada, de mal gusto y de tintes tremendistas, cuando dice que averi-

antifeminista medieval, pero se olvida que, aunque denuncia a las mujeres lascivas, el ataque se halla formulado, por otra parte, con igual severidad a los hombres lujuriosos. Se apoya Martínez de Toledo en el libro III del tratado De amore de Andreas Capellanus. Véase: Deyermond, A. D., Historia de la literatura española. La edad media. Traducción castellana de Luís Alonso López. Ed. Ariel. Barcelona-Caracas-México. 1976. Pp. 249-250.

9. Martínez De Toledo, A., Arcipreste de Talavera. Corbacho o reprobación del amor mundano. Ed. De Carlos Sainz de Robles, Clásicos españoles. Ed. Ferni. Genève. 1973. P. 254. Véase: Richthofen, E. V., «Alfonso Martínez de Toledo und sein «Arcipreste de Talavera», ein kastiliches prosawerk des 15 jahrhunderts», trabajo publicado en Zeitschrift für romanische philologie, 61. Buchdruckerei des waisenhauses. Halle. 1941. Pp. 417-537.

10. Ibidem, p. 254.

11. Ibidem, pp. 255-256.

12. RoIG, J., Llibre de les dones o Spill. op. cit. p. 76. Para facilitar la rima escribe meses por mesos.

13. El narrador del Llibre de les dones o Spill es un personaje que no puede identificarse con el autor Jaume Roig, médico de la reina María de Castilla, esposa de Alfonso el Magnánimo, y administrador del famoso hospital de En Clapers, hospital de los beguinos. Véase: TeIXIDOR, F. J., Antigüedades de Valencia. Obser- 
guando e inquiriendo sobre su honestidad, se descubrió la fechoría cometida por la beatita, con gran vileza: encontrándose preñada poco más o menos de unos tres meses y con ciertas tomas diabólicas, dos criaturas hízose sacar y abortar secretamente.

El propósito del autor de Spill ${ }^{14}$, según la consulta dirigida al caballero Joan Fabra que inicia el libro, es demostrar que todas las mujeres son viles, a excepción de la Virgen María, y aconseja a los hombres que se aparten de ellas. Para ello emplea expresiones propias de la lengua coloquial cuando se refiere a la beata del texto anterior: roseg altàs (rosega-altars), persona de cuella torcido y roealtares. El hecho de que fuera a vivir al bovalar/dels Agostins, / entre'ls Beguins/ $e$ Sant Francesc, es un indicio de que la mujer vilipendiada era beguina y que, tal vez, pertenecía a laTercera Orden de San Francisco (terciaria franciscana) ${ }^{15}$.

En la composición satírica Col-loqui de Dames, cargada de tonos más o menos escabrosos, la sexualidad es el eje temático de este poema anónimo, perfilándose, incluso, rasgos pornográficos.

En este coloquio, empleando palabras impúdicas, se reproduce la conversación de tres mujeres (una casada, una viuda y otra beata de condición) en el interior de la Seo (de la catedral) de Valencia durante la celebración de los solmenes oficios de viernes santo, lo que añade un carácter más indecente y sacrílego. El diálogo, además de una descarada irreverencia al lugar sagrado donde se desarrolla, refleja una punzante sátira antirreligiosa. Lo sorprendente de esta conversación obscena es que una de las dialogantes sea una beata.

En esta despiadada invectiva, en este sarcasmo, se ataca a las monjas, a las beguinas y al clero. Dice la mujer casada: no encuentro monja ni beguina/ sin envidia,(no trob monja ni beguina/ sens enveja) ${ }^{16}$. La obra está repleta de ironías repulsivas, de murmuraciones y de metáforas eróticas sobre la inmoralidad de los sacerdotes y sobre sus inclinaciones amatorias. Se considera que la visita a la iglesia y la confesión, en clara referencia a los abundantes religiosos «solicitantes», no son sino un subterfugio para la práctica erótica. Dice la beata de

vaciones criticas donde con instrumentos auténticos se destruye lo fabuloso, dejando en su debida estabilidad lo bien fundado. Escribiólas en 1767 Fr. Josef Teixidor, 2 Tomos, imprenta de Francisco Vives Mora, Valencia, 1895. Capítulo VII, Libro VII, del tomo II. Rubio Vela, A., RodRigo Lizondo, M., «Els beguins de València en el segle XIV. La seua casa-hospital i els seus 1libres» en Quaderns de Filologia, Miscel·lània Sanchis Guarner, Universitat de València. 1984.

14. Se ha relacionado el Spill con la novela picaresca castellana, sobre todo con el Lazarillo de Tormes, donde también se narran las aventuras del protagonista en primera persona.

15. Véase la Introducción de Albert HaUf al libro de Josep Pou i MARTí. Visionarios, beguinos y fraticelos catalanes (siglos XIII-XV). Instituto Juan Gil Albert. Diputación Provincial de Alicante. Alicante. 1996. p. 23.

16. Pitarch, V., Gimeno, L1., Poesia erótico i burlesca dels segles XV i XVI. Volum I. Núm. 63. Ed. Eliseu Climent. Valencia. 1982. p. 49. 
un canónigo: Be deu fotre en un arret/vegades dos ${ }^{17}$; y de los curas, a los que tot lo món los té per mestres son diestros en el amor: nostre vicari,/ un hipòcrit e falsari/ robador:/ de santedat dóna color,/ $i$, confessant,/ los engolans, los va cercant/ com un furó ${ }^{18}$.

Todas las referencias eróticas van introducidas por la propia descripción lujuriosa del cuerpo de la casada (prosopografía lasciva):

En cos no veig taca lletja

sinó en lo meu;

una singular faisó ${ }^{19}$ veureu:

tinc pits e cuixes

plenes, llises, no pas fluixes,

i com blanques!

Pus rodones tinc les anques

que un tonell,

que si em vésseu lo ventrell,

vos senyarieu

així és petit, que no creurieu

de dona fos ${ }^{20}$;

Dice la descarada beata: No ho sap qui no s'és vist/ tocat de broca! ${ }^{21} /$ Lo dolç fruit ix de la soca/ naturalment, / i per ço tot hom impotent/ és desamable; $i$ voldriem un diable/ que ens ho fes ${ }^{22}$... Y contra los canónigos: A Déu faria sacrifici/ qui cremàs/ aquest canonges, en un ras $^{23}, /$ el bisbe $i$ tot;/ mai veureu que diguen mot/ d'Hores ni Missa ${ }^{24}$...

17. Ibidem, p. 59. «Arret», gal. «Aturada, embranzida» (En un impulso, en un arranque).

18. Ibidem, p. 63.

19. Faisó: figura.

20. Ibidem, p. 49. «En cuerpo no veo ninguna mancha fea/ sino en el mío;/ una singular figura veréis:/ tengo pechos y muslos/ llenos y lisos, no flojos,/ y que blancos!/ Más redondas tengo las nalgas/ que un tonel,/ que si me vieseis el estómago/ os santiguaríais/ así es pequeño, que no creeríais/ que fuese de mujer...»

21. Broca: instrumento de carpintero. Barrena de boca cónica que se usa con las máquinas de taladrar. Aquí, la palabra tiene connotaciones eróticas.

22. Ens ho fes: figura retórica que tiene, también, connotaciones sexuales.

23. En un ras: sin contemplaciones.

24. Ibidem, p. 58. «A Dios haría sacrificio/ quien quemara/ estos canonjes, sin contemplaciones,/ al obispo y todo;/ nunca veréis que digan palabra/ no horas ni misas». El léxico empleado en el Col-loqui de Dames es áspero y grosero (bròfec), como el empleado por Jaume Roig y por otros escritores valencianos de su época: Joanot Martorell, Bernat Fenollar, Jaume Gassull (Lo procés de les olives, Lo somni de Joan Joan). La brofeguesa, la grosería y el mal gusto de estos satíricos. 
La casada cita a Boccacio, recordando que habla mal de las mujeres: $\mathrm{Ha}$ veu vist Joan Boccacci ${ }^{25}$ / quant mal ha dit/ De nosaltres? S'és partit/ amb lo Corbatxo. ${ }^{26}$. Y finalmente, habla de la viuda, con extremada crudeza: No ha molt que he parit/ d'un capellà,/ e ja só prenys d'un escolà,/ sabut, donós/ franc, xamús $i$ valerós/ e ben parlant;/ ardit, diligent e puixant/ e molt secret ${ }^{27}$.

En el Sermó del Bisbetó (Sermón del Obispillo) de finales del siglo XIV, el autor anónimo dedica un fragmento a las beatas, título bajo el que coloca también a las beguinas. La crítica se limita a ciertas pinceladas irónicas. Dice, refiriéndose a ellas: Més depenen en sabates/ que los correus (gastan más en zapatos que los correos); l'ús e práctica segueixen/ de les raboses (siguen el uso y la práctica de las zorras) ${ }^{28}$.

El Sermó del Bisbetó ${ }^{29}$, que empieza siendo un poema religioso, con la narración de la historia de los Reyes de Oriente y de Herodes, el nacimiento de Cristo y la degollación de los Inocentes, se convierte en una viva sátira contra las diversas jerarquías eclesiásticas.

El autor anónimo del Sermó del Bisbetó se adelanta a los erasmistas (preerasmismo) satirizando contra las peregrinaciones. No es necesario ir a Santiago para obtener perdones y para santificarse, sino que es suficiente cumplir religiosamente con el papel que cada uno tiene en el orden social y cívico:

25. Referencia a la misoginia de Boccaccio, autor que tenía muchos seguidores, tanto entre los escritores de la Corona de Castilla como de la Corona de Aragón. Una muestra de la difusión de sus obras (Decameron, 1351; La elegía de doña Fiameta; el Corbacho fue la traducción del Corbaccio (1397) por Narcís Franc

26. Pitarch, V., Gimeno, Ll., Poesia erótica i burlesca dels segles XV i XVI. op. cit. pp. 69-70.

27. Ibidem. pp. 75-76. Leyendo estos versos podemos comprender que Ramón Miquel i Planas, al reeditar el Col-loqui de Dames lo consideraba: obra de una perversión pocas veces igualada en la literatura, (obra d'una perversió poques vegades igualada en literatura). Citado por Vicent Pitarch y Lluís Gimeno. Véase: Miquel i Planas, R., Cançoner satíric valencià dels segles XV i XVI, publicado en la serie «Biblioteca catalana». Barcelona. 1911. Véanse en esta línea satírica y procaz: Poemes satírics del segle XV. I. El procés de les olives (València, 1497). Edició facsímil amb un pròleg de V. Andrés Estellés, estampat per Lope de la Roca, alemany. Valencia. 1973. Poemes satírics del segle XV. II. Lo somni de Joan Joan (València, 1497). Edició facsímil amb una noticia bibliográfica per Josep Palacios. Valencia. 1974. Véanse obras de Bernat Fenollar y Jaume Gassull (Gaçull)...

28. El segundo Sermó del Bisbetó, así como el primero, sigue la tradición del episcopus puerorum. Es una parodia del sermón dedicado a la crítica social. Tiene carácter satírico, tanto cuando habla de los religiosos como cuando habla de las mujeres. Sobre este Sermó del Bisbetó, véase: De Riquer, M., Comas, A., Història de la literatura catalana. Tomo II. Ed. Ariel. Barcelona. 1980. pp. 78-84. Hay otros textos en los que también se ponen de manifiesto los defectos de ciertas mujeres: veguinas, bigardas, beatas y monjas. Véase el famoso proceso inquisitorial de El cavaller i l'alcavota, o falsa «beguina», Estudio preliminar, pp. 23-26 de Albert Hauf I VALLs, en Visionarios, beguinos y fraticelos catalanes (siglos XIII-XV), obra de J. Pou y Martí, O.F.M, op.cit.

29. Rodríguez Puértolas, J., Alpera, L1., Poesía societat a l'Edat Mitjana. Ed. Moll. Palma de Mallorca. 1973. pp. 264-265. 


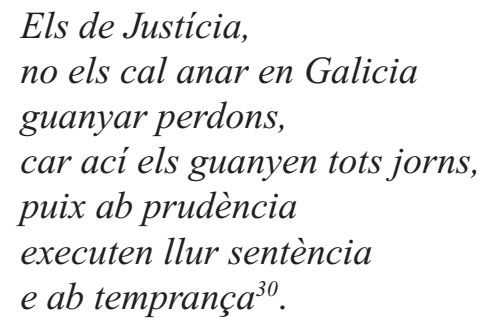

Una gran parte del largo poema está dedicado a las mujeres, siguiendo la tradicional corriente misógina. Sobre el origen de las beguinas en Flandes (Bélgica), dos opiniones dividen a los eruditos ${ }^{31}$. Unos investigadores opinan que las beguinas fueron fundadas por Santa Begge (o Begh), hija de Pepino de Landen (siglo VII) $)^{32}$ y otros atribuyen la fundación de la Orden a Lambert Begh o le Bègue (muerto en 1177), llamado así parce qu'il bégayait (porque tartamudeaba). Este célebre predicador, canónigo de Lieja, vivió durante la segunda mitad del siglo XII. Pero, ¿cuándo aparecen estas primeras congregaciones, antes o durante la etapa que vivió Lambert le Bègue? En cuanto a la etimología de la palabra «beguina», la cuestión queda aclarada si admitimos que fue el fundador Lambert le Bègue. A pesar de todo son interesantes otras teorías sobre la etimología de esta palabra. Según algunos estudiosos, podría derivarse del verbo alemán beginnen o beghinnen (comenzar, principiar), porque es como «comenzar» con el primer paso de la vida religiosa. Otra etimología, defendida por Fisen y Grammaye ${ }^{33}$, afirma que las beguinas han recibido este nombre a causa de su cofia, llamada en francés béguin. Ducange ${ }^{34}$ y otros dicen que las palabras bégard y béguine proceden del anglosajón began o bigan; todavía en el inglés actual to beg, pedir, mendigar; o de beggar, mendigo; o de to begin, empezar. Alguien lanzó la idea de que la palabra «beguina» era un derivado del vocablo castellano «beata» o del vocablo italiano binzoccha.

30. Ibidem, p. 265.

31. Sobre el origen de las beguinas, véase el trabajo de O'SHERIDAn Paul, publicado en Revue Belge d'Histoire. Primer Año. Volumen I. Bruselas. 1914.

32. Vid: Iosepho Geldolpho A Ryckel Aв Oorbeeco. Vita S. Beggae Dicissae Brabatiae andetennensium begginarum, et beggardorum fundatricis. Typis Corn. Coennesttenii. Lovaina. 1631.

33. Terwecoren, M., Opinions sur l'origine des béguinages belges. Lib. De H. Goemaere, ucc. Vanderboght. Bruselas. 1852. p. 63.

34. Wytmans, K1., Des béguinages en Belgique. H.Hoste. Libraire-Éditeur. Gand. 1862. P. 15.

Véase: Mierlo J. Van., «Béguins, Béguines, Béguinages» en Dictionnaire de spiritualité. Publié sur la direction de Marcel Miller, S. J. Facicule V. Gabriel Beauchesbe et ses Fils Éditeurs. París. 1935; también: Greven, J., Die Anfänge der Beginen. Ein Beitrag zur Geschichte der Volksfrömmigkeit und des Ordenswesen im Hochmittelalter. Vorrefornationsgeschichtliche Forschungen. Volumen III. Münster. Archendorffsche Verlagsbuchandlung. 1912. 
Un caso bien distinto es la animadversión que demostraban algunos escritores hacia los beguinos, beguinas y franciscanos espirituales fue la sincera aproximación respetuosa del médico valenciano Arnau de Vilanova $(+1311)$, que los defendió siempre en sus obras religiosas y exegéticas, hasta tal punto que, en tiempo del papa Clemente $\mathrm{V}$, con su prestigio ante las cortes real y pontificia, sería el más grande soporte de estos grupos reformadores que defendían la verdad evangélica, eran partidarios de hacer penitencia en hábito seglar y de vivir en la pobreza apostólica, tal como leemos en el tratado religioso de Arnau de Vilanova, Raonament d'Avinyó, en el que delata la persecución que sufrían los beguinos y las beguinas ${ }^{35}$ :

La segona manera per què s'és manifesta en ells la damunt dita furor de perseguir la veritat evangelical, és en les pressones seglars, les quals volen fer penitència en àbit seglar, e viure en pobrea e menyspreu de si metexs, axó com són beguins e beguines ${ }^{36}$.

Arnau de Vilanova, en su tratado Lliçó de Narbona, clama contra la corrupción del clero, contra su afán de ganar riquezas, contra la simonía y vanidad, insistiendo en la necesidad de vivir en la pobreza, tal como enseñó y como hizo Jesucristo:

Per ço és caygut lo diable en los christians, ço és, en clergues e religiosos e setglars; e jahen en foch de cobesa e de guanyar e multiplicar riqueses en totes maneres desordenades, axí com és usura, barats, engañar, e simonía, roberia e homicidi, e tots altres vicis per què puixen mantener aquella vanitat e superfluïtat $^{37}$.

En el mismo tratado, presenta el ejemplo que Jesucristo dio a los mortales eligiendo la pobreza:

Altre exemple que donà, observan ab los mortals, fo exemple de elegir e de amar pobresa en aquest segle ${ }^{38}$, car volch néxer de mare pobra, en locho $n$ tan solament nacían los pobres, ço és, en hun racó de plaça pública; e volc ésser, a son neximent, embolcat de vils draps... ${ }^{39}$

35. Como ampliación de todo esto, véase mi trabajo: SAnTonjA, P., «Arnau de Vilanova i la seua relació amb els beguins i espirituals: els origens d'aquestes congregacions i llurs ideals religiosos» en EF. Vol. 92, eneroagosto, núm.s: 400-401. Barcelona. 1991. pp: 25-53.

36. Raonament d'Avinyó, en: Vilanova, Arnau de. Obres catalanes. Volumen I. Escrits religiosos, a cura de P. Miquel Batllorí, S.I., Prólogo de Joaquim Carreras y Artau. ENC. Ed. Barcino. Barcelona. 1947. p. 206.

37. Lliçó de Narbona, en: Vilanova, Arnau de., Obres catalanes. Volumen I. Escrits religiosos, a cura de P. Miquel Batllorí, S.I., Prólogo de Joaquim Carreras y Artau. ENC. Ed. Barcino. Barcelona. 1947. pp. 158159.

38. Exaltación de la pobreza de Cristo, muy característica de los beguinos y de los franciscanos espirituales, que tanto defendió Arnau de Vilanova.

39. Ibidem, p. 143. 
Los espirituales de Provenza, discípulos de fray Hug de Disa, tuvieron como dirigente ideológico a Pierre Déjean Olieu (Pedro Juan Olivi), considerado como el fundador de la secta de los beguinos; mientras que los espirituales de Toscana seguían las doctrinas de Ubertino de Casale, autor del polémico libro Arbor vitae crucifixae Jesuchristi. Unos y otros eran partidarios de la pobreza evangélica, eenmigos de la ciencias teológicas y, en los últimos tiempos de su existencia, rebeldes, joaquinistas y con peligro constante de errores contra la fe. Sobre los beguinos de la Corona de Aragón, a pesar de los trabajos de Josep María Pou i Martí, de Roc Chabàs, de Josep Perarnau, de Salvador de les Borges, de Francesco Santi y de otros investigadores, todavía nos movemos en el campo de las conjeturas, de las hipótesis y las contradicciones. Según Josep Perarnau, apoyándose en el inventario editado por Roc Chabàs, ya existía un grupo de beguinos en Valencia en vida de Arnau de Vilanova, y éste ejercía sobre ellos una cierta dirección doctrinal ${ }^{40}$, surtiéndolos de libros, que él mismo les daba o dejaba. Sabemos que Arnau ejercía una influencia doctrinal sobre Pere de Montmeló ${ }^{41}$, uno de sus albaceas, y sobre Bernat de Clapers, procurador de Arnau de Vilanova y fundador del hospital Infirmi Pauperes Christi ex ómnibus eorum necessitattibus, que llevaría su nombre ${ }^{42}$. En el Concilio de Tarragona, celebrado en febrero de 1317, se prohibía a las beguinas, bajo pena de excomunión, hacer vida comunitaria, llevar mantos y otras prendas de vestir características de las beguinas y beguinos, leer libros de teología en lengua vulgar ${ }^{43}$ y predicar sin autorización:

40. ChabÀs, R., «Arnaldo de Vilanova y sus yerros teológicos», en Homenaje a Menéndez Pelayo. Volumen II. Estudios de erudición española. Librería General de Victoriano Suárez. Madrid. 1899. Uno de estos seguidores de Arnau sería Ramon de Conesa (en Conesa), albacea y administrador de sus bienes. p. 368.

41. Perarnau, J., «L'alia informatio beguinorum»d'Arnau de Vilanova. Studia. Textos. Subsidia-II. Facultat de Teología de Barcelona, Secció de Sant Pacià. Barcelona. 1978. p. 131: «la noticia de l'existència d'un grup entorn Pere de Montmeló, vinculat a una institució caritativa i hospitalària, és gairebé la confirmació definitiva d'aquella paternitat arnaldiana i obliga a plantejar una pregunta: ¿el grup de Pere de Montmeló és el mateix que tres anys més tard es trobà a «la honor e cases» de Jacme Ces Fonts? D’altra manera: ¿a Barcelona, abans de 1316 hi hagué una o dues comunitats arnaldianes?». Véase del mismo autor: "Troballa de tractats espirituals perduts d'Arnau de Vilanova», 1-2. Revista Catalana de Teologia. Facultat de Teología de Barcelona, Secció de Sant Pacià. Barcelona. 1976. pp. 489-512.

42. Sobre Bernat de Clapers, véase la aportación del historiador dominico del siglo XVII, Josep TeIXIDOR. Antigüedades de Valencia. Observaciones ccríticas donde con instrumentos auténticos se destruye lo fabuloso, dejando en su debida estabilidad lo bien fundado. Tomo II. Imprenta de Francisco Vives Mora. Escribiólas en 1767. Valencia. 1895. p. 287. Véanse también: RuBio VelA, A., «Un hospital medieval según su fundador: el testamento de Bernat des Clapers (Valencia 1311)» en Dynamis, 3. Granada. 1983. p.377. Del mismo autor: «Una fundación burguesa en la Valencia medieval: El Hospital de En Clapers (1311)» en Dynamis, 1. Granada. 1981. pp. 17-49.

43. Pou I Martí, J. M., Visionarios, beguinos y fraticelos catalanes (siglos XIII-XV). Ed. Seráfica. Vich. 1930. p. 100. Perarnau, Josep en su L'Alia informatio beguinorum d'Arnau de Vilanova, op. cit. También dice que el Concilio de Tarragona se celebró en el 1317, p. 53. Rodrigo Elizondo, Mateu, en «La protesta de Valencia de 1318 y otros documentos inéditos referentes a Arnau de Vilanova», en Dynamis, I. Granada. 
Siendo cierto que en algunas partes de la provincia de Tarragona se siembran y enseñan errores y herejías por ciertos hombres y mujeres... ordenamos para siempre que los begardos y beguinas que forman muchos como pequeños conventos, no vivan juntos... no llevarán capotes, ni otro traje que el ordinario, no sea que parezca que introducen un nuevo método de vida no aprobado por la Iglesia...44

II. Contra beguinos y beguinas.

Beguinae et beguini plures, quasi conventicula facientes, simul non stent, nec etiam duo in eadem domo, nisi casualiter et unum diem ad plus, vel ratione consanguinitatis verae et propinquae (propias en la versión de Perarnau) qui etiam, si non esset beguin, simul alias habitarent. Mantellos non portent, nec conjuncta praeter modum communem, ne novum ritum vivendi et ab Ecclesia non aprobatum introducere videantur; nec audeant congregari ad legendum aliquid, dicendum vel repetendum nisi in ecclessis, prout aliis laicis fidelibus est permissum...

III. Ne habeant libros theologicos in vulgari.

Statuimus etiam et ordinamus, quod nullus beguinus vel beguinae teneat, habeat et legat libros theologicos in vulgari, nisi libros in quibus solum orations continetur; et habentes praedictos volumes, quod ad tradendum ipsos diocesanis per censuram ecclesiasticam compellantur ${ }^{45}$.

La vida comunitaria era uno de los puntos conflictivos de la experiencia beguina. Los beguinos, como todos los movimientos espirituales de la Edad Media, deseaban seguir el ejemplo de la iglesia primitiva:

Encara més, avem ö̈d prë̈car que en la primitiva esgleya, tots aquels qui creÿen eren ensems e avien totes lurs coses comunes ${ }^{46}$.

El papa Juan XXII proclamó la bula que comienza Gloriosam Ecclesiam (1318), la cual mandaba que los franciscanos espirituales y beguinos, principalmente aquéllos que se habían refugiado en Sicilia bajo la protección del rey Federico, debían ser castigados y entregados a lo superiores de la Orden ${ }^{47}$. Una prueba de la acogida que dispensó el rey Frederic a los espirituales y beguinos

1981, dice: El Concilio tuvo lugar en Tarragona en febrero de 1318, presidido por el arzobispo Jimeno de Luna, p. 250.

44. Arranz, A., «El demonio femenino. Mujer, Iglesia y religiosidad en el bajo Medievo hispánico» en Historia 16. Año VIII. Núm. 91.

45. Pou i Martí, J. M., Visionarios, beguinos y fraticelos catalanes (siglos XIII-XV) op. cit. p. 101. También ha sido publicado este texto, parcialmente, por Josep Perarnau, en L'Alia informatio beguinorum d'Arnau de Vilanova, op. cit. p. 53.

46. Perarnau, J., L'Alia informatio beguinorum d'Arnau de Vilanova, op. cit. p. 51.

47. No olvidemos que muchos beguinos pertenecían a la tertia regula B. Francisci (terciarios) y, por tanto, compañeros espirituales de los franciscanos. 
son las repetidas cartas que le escribe su propio hermano Jaime II, en las que le pedía que expulsara de su reino a aquellos rebeldes y en las que se lamentaba de que Federico continuara protegiéndolos.

Arnau de Vilanova, todo lo contrario, aconsejaba al rey Federico (1310) en la Informació espiritual al rei Frederic de Sicília que debía defender a los beguinos:

Lo primer bé que suscitarets en los crestians será que cells qui amen la veritat del crestianisme e ara están amagats axí com perles en arena e moxons en barça d'espines e tortres en selva per la multitud e lo poder dels adversaris, segons que dien lres revelacions divinals, trauran lo cap defora, e manifestar $s$ 'an, e parlaran ardidament, e obraran palesament, e encendran e enflamaran los altres ${ }^{48}$.

Arnau de Vilanova piensa que el rey Federico es el designado por Dios para proteger a los francsicanos espirituales y a los beguinos contra la Iglesia de la carne: Mas yo veyg clarament que Déus appells vos especialment a aquest ministeri, e, si no en vós roman, a vós vol donar aquesta honor ${ }^{49}$. El rey Federico tenía al médico valenciano como consejero espiritual y político, siguiendo alguna de sus directrices: fundar hospitales para los pauperes Christi ${ }^{50}$, acoger a los beguinos, perseguidos en todas partes...

Arnau mantuvo estrechas relaciones con los beguinos, sobre todo después de 1305. Algunos de sus escritos, como por ejemplo, Alia informatio beguinorum, son una defensa de la espiritualidad beguina frente a ciertas posiciones de la jerarquía eclesiástica, del mismo modo que la Lliçó de Narbona. Otras obras, como la misma Informació espiritual o el Alphabetum catholicorum, dedicadas a reyes, son apologías de aquella espiritual laical que propagan los beguinos ${ }^{51}$.

48. Vilanova, Arnau de., Información espiritual al rei Frederic de Sicília, en Obres catalanes. Volum I. Escrits religiosos, op.cit. pp. 239-240. Los que están escondidos son los beguinos. Por eso Arnau suplica al rey Federico que los proteja.

49. Vilanova, Arnau de., Información espiritual al rei Frederic de Sicília, op. cit. p. 242.

50. Arnau de Vilanova es un gran propulsor de estos centros de misericordia para pobres. Nota curiosa es la distinción que hace entre «pobres de penitencia» (beguinos y espirituales de Provenza) y los otros pobres. Los pobres de penitencia eran los que practicaban el usus pauper de Pierre Déjean Olieu (Olivi), l'usage pauvre. (Se pueden consultar: DuRIEux, F. R., «Un manuscrit occitan des spirituels de Narbonne au debut du XIV siècle. Essai d'interpretattion franciscaine», en Cahiers de Fanjeaux, 10, Toulouse, 1975, pp. 239-240: L'idée d'usage pauvre par lequel s'était tant battu Olieu (Olivi) venait naturellement de saint François, et saint Bonaventure n'avait pu que le ratifier.

51. Las obras Epistolam ad gerentes zonam pelliceam, Epistola ad priorisam de caritate, De helemosina et sacrificio, Per ciò che molti, De humilitate et patientia Iesu Christi o la Epistola ad Bartholomeam Montaneri, nacieron en buena parte de la relación de Arnau con los beguinos. (Vid. Mensa i Valls, J., Arnau de Vilanova. «Episodis de la Història». 313. Rafael Dalmau, editor. Barcelona. 1997. p. 32. 
Algunos beguinos y beguinas se contaminaron de doctrinas heréticas, pero no ocurrió lo mismo con las beguinas del norte de Europa. En Brujas, en Gante y en otras ciudades de Flandes, los béguinages siguieron fieles a la ortodoxia católica. De todas formas, ciertas tendencias de los beguinos y beguinas, su culto ferviente y místico de la continencia. Así como la pobreza evangélica, eran motivos suficientes para ser sospechosos de herejía ${ }^{52}$. A pesar de que las beguinas de Bélgica, como ya hemos dicho, permanecieron dentro de la más pura ortodoxia, también sufrieron ataques y persecuciones, hasta que el papa Juan XXII dejó bien claro que ellas no estaban de ninguna manera incluidas en el anatema de Clemente V, rogando a los obispos que las ayudaran y las socorrieran. Durante los primeros años del siglo XIV, el béguinage de la ciudad de Saint-Trond (13021329), ciudad que había sido excomulgada en dos ocasiones, vivió una época muy dramática, principalmente a partir de 1314 con los ataques de los Sainttronnaires de Adolphe de la Mark, Príncipe-Obispo de Lieja ${ }^{53}$.

La preocupación de las beguinas, algunas de ellas, como ya hemos dicho, contaminadas de doctrinas heréticas, no sólo era espiritual y cultural, sino que era también la búsqueda de un asilo que las protegiera de las inexorables exigencias y las escasas oportunidades que ofrecía la vida familiar ${ }^{54}$.

Es verdad que, a finales del siglo XVIII y a principios del XIV, muchísimos beguinos y beguinas abrazaron la Tercera Orden de San Francisco de Asís, como también lo es que muchos, a causa de perversos contactos con los cátaros y valdenses, se mancillaron con diversos errores y prácticas $^{55}$, hasta el extremo que en

52. Mierlo, J. Van., «Béguins, béguines, béguinages», en Dictionnaire de Spiritualité, publié sous la direction de Marcel Viller, S.J. Fascicule V. Gabriel Beachesne et ses fils éditeurs. París. 1935. Col. 1344.

53. Straven, F., Notice historique sur le Béguinage dit de Sainte-Agnès à Saint-Trond. Tipographie E. SchoofsHerman. Saint-Trond. 1876. pp: 14-15.

Todavía en 1623, reinando en España Felipe IV y gobernando los Países Bajos Isabel Clara Eugenia (hermana de Felipe II, muerto en el año 1621, y ya viuda del Archiduque Alberto de Austria, muerto también en el año 1621), el béguinage de Saint-Trond atravesaba momentos dramáticos. En 1620, cuando iba a finalizar la tregua, las beguinas de Flandes pedían protección a la Infanta Isabel Clara Eugenia y ésta, movida por la piedad hizo un documento (1623) que protegía las casas de Dios contra los peligros de la guerra. Este documento ha sido publicado por François Straven en Notice historique sur le Béguinage dit de Sainte-Agnès à Saint-Trond. op. cit. pp: 26-27. Y que yo copio, respetando la grafía del francés antiguo tal y como está en el documento: Isabel Clara Eugenia, par la grâce de Dieu Infante d'Espagne, etc... nous avons prins et mis, comme par cestes prenos et meettons en la protection et sauvegarde especialle de sa Mate et la nre les dames Religieuses du Béguinage proche la porte de la ville de St-Trond... vos mandans partout et commandans au nom et de la part de sa Maté et à chun de vous en droict soy, et sy comme à Luy appartiendra beni expressément de ne loger, ny permettre que soyent logez aud béguinage par qui que ce soit aulcus gens de guerre sans expresse notre ordonnance ou du mareschal dels Host... (p. 27).

54. King, M. L,. Mujeres renacentistas. La búsqueda de un espacio. op. cit. p: 152.

55. Pou i Martí, J. M., Visionarios, beguinos y fraticelos catalanes. Ed. Seráfica, op. cit. pp. 21-25. No todos los beguinos se hicieron terciarios ni todos los terciarios eran beguinos, y aunque algunos de ambos 
un momento dado el nombre beguina tenía un sentido injurioso y se empleaba para calumniar la ortodoxia de estas mujeres: praedictarum mulierum religionem malitiose infamantes. La palabra beguino llegó a significar, por tanto, hereje.

El ideal beguino de la soltera, consagrada a la virginidad, al estudio y al servicio de los necesitados, llegó a su cumbre a principios del siglo XIV y fue resultado de una profunda renovación religiosa ${ }^{56}$. Este movimiento se asocia, con frecuencia, con las ciudades del norte de Europa donde se unió la devotio moderna o «nueva devoción», iniciada por Gerhard Groote, quien convirtió su propia casa en hogar para hermanas de la «Vida Común» en 1374. Al igual que la beguinas, estas mujeres hacían votos informales de castidad, usaban vestidos simples, realizaban labores manuales y profesaban la imitación de $\mathrm{Cristo}^{57}$.

A las mujeres se les había abierto otra orientación religiosa, agrupándose en un movimiento en el que se rompía el tradicional esquema monacal o conventual: son las beguinas, que llevaban una vida en común, pero no claustral. Mientras monjas y abadesas estaban sometidas a la clausura, a los votos perpetuos y a la jerarquía eclesiástica, las beguinas vivían en libertad, respetando las normas establecidas por la comunidad ${ }^{58}$. No emitían votos oficiales ni perpetuos, sino privados y durante el tiempo que vivían en el Béguinage (Beaterio). No hacían voto de pobreza, conservando cada una sus derechos a la propiedad privada. Los votos que hacían eran el de castidad y el de obediencia, llevando una vida sobria y sencilla. Trabajaban para mantenerse. El trabajo manual consistía generalmente en la manufactura o preparación de la lana, así como la educación de las niñas ${ }^{59}$. No son monjas en el sentido estricto. Su espacio es el Béguinage o

grupos se adhirieron a la herejía, hallamos otros beguinos y terciarios bien ortodoxos y protegidos por la Iglesia.

56. KING, M. L., Mujeres renacentistas. La búsqueda de un espacio. op. cit. p. 141. Las comunidades beguinas comenzaron a formarse en Bélgica y Alemania en el siglo XIII. El mayor incremento en el número de beguinas y religiosas asociadas a éstas ocurrió en las cuatro décadas que precedieron al 1318, año en que se publicó la legislación restrictiva del Concilio de Vienne. (Ibidem, p. 140).

57. Ibidem, p.141.

58. Hubo casos excepcionales en los que las abadesas y prioras de monasterios y conventos podían tener cierta autonomía, como fue el caso del Monasterio de las Huelgas de Burgos. Este monasterio era una fundación real en el que ingresaban las altas damas de la nobleza, hijas naturales de reyes y los altos nobles, princesas... ¿quién se atrevía a enfrentarse con la gran abadesa de las Huelgas, quién podía arrebatarle sus grandes privilegios? Tal poder llegó a alcanzar que, según un proverbio popular y malicioso, «si el Sumo Ponífice, cabeza de la Iglesia, tuviera que tomar esposa lo haría, sin duda, eligiendo a la Abadesa de las Huelgas por su enorme preeminencia». (Véase: Escrivà de Balaguer, J. M., La Abadesa de las Huelgas. Estudio teológico-jurídico. Ed. Rialp. Madrid. 1974).

59. Redondo, V., «Los movimientos femeninos en tiempos de Francisco de Asís» en EF. Volumen 93. Mayodiciembre. Núm.s: 404-405. Barcelona. 1992. pp. 197-239. Cita de la página 223. Véase EPINEY-BuRGARD, G., Zum Brunn, E., Mujeres trovadoras de Dios. Traducción de María Tabuyo y Agustín López. Ed. Paidós. Barcelona. 2000. El movimiento beguino nació en Bélgica, alrededor del año 1170. Jacobo de Vitry, protec- 
beaterio (beginenhaus): casitas agrupadas, rodeadas de un muro con una puerta de entrada, que se cierra por las noches, y un gran patio (beginenhof), con una iglesia y un cementerio ${ }^{60}$.

Son distintos los factores que influyeron en la propagación de este movimiento de mujeres, pero uno de ellos pudo ser la fundación de los llamados monasterios dobles de mujeres y hombres que, durante el siglo XII, se intentaron abolir gradualmente por motivos de honestidad y por tendencias misóginas.

La Iglesia institucional y corrupta, con el poder temporal y espiritual, con sus riquezas, la venta de indulgencias, las excomuniones, las simonías, los nepotismos y los grandes privilegios, tenía que ver con cierto recelo a estos movimientos utópicos (franciscanos espirituales, beguinos, beguinas y fraticelos) que pretendían volver a la pobreza evangélica y a la vida comunitaria de la Iglesia primitiva, siguiendo las doctrinas de Pedro Juan Olivi ${ }^{61}$. Algunos seguidores de Olivi y de Joaquín de Fiore constituyeron grupos con tendencias apocalípticas. Estos visionarios eran joaquinistas que se creían favorecidos con visiones sobrenaturales. Empleaban un lenguaje enigmático, esotérico y apocalíptico, profetizando, algunas veces, dando fecha exacta de algún acontecimiento maravilloso.

Como veremos más adelante, estas mujeres, con frecuencia, fueron sospechosas de herejía y su situación fue analizada en el Concilio de Vienne (Francia) de 1311, cuando el papa Clemente V condenó el movimiento beguino, permitiendo, no obstante, que las verdaderas beguinas, fieles a la ortodoxia, vivieran juntas en sus hospicios o béguinages. Esto salvó a una inmensa mayoría. El papa Juan XXII, sucesor de Clemente V, defendió de forma ferviente a estas mujeres piadosas $^{62}$.

tor de las beguinas, obtuvo de Honorio III el reconocimiento de las primitivas asociaciones beguinas para Bélgica, que luego se extendieron a Francia y Alemania.

60. El viajero que vaya a Brujas puede visitar el célebre beaterio principesco de «La Viña» (Monastère de la Vigne, Monasterium de Wijngaard), que permanece igual que en el siglo XIII, fecha de su origen. La institución religiosa de las beguinas ha perdido, en la actualidad, su viejo esplendor. El Béguinage ha sido restaurado con gran respeto y en nuestros días está dirigido por una nueva congregación: «Les Filles de l'Église», benedictinas misioneras parroquiales.

61. No olvidemos que los beguinos, beguinas y franciscanos espirituales seguían ciertas enseñanzas de Olivi, sin tener en cuenta el sentido general y global de su obra. Esto no significa que, unos y otros tuvieran exactamente las mismas doctrinas, porque aunque bebieron de la misma fuente, con el tiempo se fueron alejando de sus postulados doctrinales. (Vid. JACQUES, P., «Les spirituels, l'Église et la papauté», en $C h i$ erano gli spirituali. Società Internazionale di Studi Francescani. Assisi. 1976. Leemos en la página 238: Il parait plus probable que certains affirmations des Spirituels et des Béguins prennent leur inspiration dans l'oevre de Pierre Jean Olieu et de que vingt ans de vie et de réflexions leur ont fait subir des transformations importantes.

62. Wade Labarge, M., La mujer en la Edad Media. op. cit. p. 154. 
Siempre han surgido ciertas dificultades al querer interpretar algunos documentos que tratan de beguinos, beguinas, begardos, fraticelos y franciscanos espirituales. También ha habido dificultad para deslindar el campo que distingue en general a los beguinos de los Hermanos de la Penitencia o Terciarios franciscanos, si es que no se quiere caer en el error del inquisidor Eymerich, que los define como pertenecientes a la misma secta: begardorum, beguinorum, fraticellorum vel fratrum de poenitentia de tercio ordine beati Francisci, quod idem est ${ }^{63}$.

En la Segunda Parte. Práctica Inquisitorial del Manual de los Inquisidores de Nicolau Eimeric y Francisco Peña, leemos en el apartado 27. Begardos, o beguinos, o fraticelli: Se les conoce por esto: pretenden seguir la tercera regla de San Francisco. Visten estameña ${ }^{64}$ y a veces llevan una capa. Se tocan con una capucha que les tapa casi todo el rostro. Tienen una color muy pálida, aunque generalmente son bastante gordos. Comen y beben regaladamente. Adoran los banquetes. No evitan para nada el trato con las mujeres: ¡más bien lo buscan!... En la iglesia, en vez de arrodillarse y juntar las manos como todo el mundo, se quedan de pie. Si se sientan, lo hacen en el suelo y mirando a la pared. No alzan los ojos al cielo. Unos piden caridad por la calle, otros viven siempre en casa. Atraen a su congregación a muchas putas y viven con ellas, etc ${ }^{65}$.

La identificación de la beguinas en Alemania con ciertas herejías puso en peligro la existencia de las beguinas en Bélgica durante el pontificado de Clemente $\mathrm{V}^{66}$; nos estamos refiriendo al Concilio de Vienne, convocado en el año 1311, en el cual los teológos se ocuparon de manera muy especial de los begardos y de los beguinos y las beguinas. Ya la herejía de los begardos había sido proscrita por Bonifacio VIII, y Clemente V añadió a esta proscripción la condena de las beguinas.

63. Pou i Martí, J. M., Visionarios, beguinos y fraticelos catalanes (siglos XIII-XV). op. cit. p. 21. Véase también: Grundmann, H., «Hérésies savantes et hérésies populaires au Moyen Âge» en Hérésies et Societés. Mouton. París-La Haya. 1968. Y del mismo autor: «Zur Geschichte der Beginen in 13. Jahrhundert» en Archiv für kulturgesichte. 21. Münster. 1931. pp. 296-320.

64. Estameña: tejido de lana, sencillo y ordinario, que tiene la urdimbre y la trama de estambre.

65. Eimeric, N., PeÑa, F., El manual de los inquisidores. Introducción y notas de Luis Sala-Molins, traducido del francés por Francisco Martín. Muchnik Editores. Barcelona. 1983. p. 160. Véase también: EyMERICI, O.P., Directorium Inquisitorum. Barchinonae. Joannes Luschner. Alemanus. 28 de septiembre de 1503. Ejemplar muy valioso, que he podido consultar en el Archivo de la Catedral de Segovia, con la Signatura: A. 290, en Libros raros.

66. Efectivamente, las beguinas de Alemania se hicieron «teólogas» y empezaron a disputar sobre la esencia divina, sobre la Trinidad, sobre los misterios de los sacramentos y a querer penetrar en la profundidad de los artículos de la fe; actividad peligrosa que fue para ellas el origen de una fuente de errores. Véase: GRUNDMANN. H., «Religiöse bewegungen im mittelalter. Untersuchungen über die geschichtlichen grundlagen der deutschen mystik», en Historia Studien. Berlín. 1935. p. 267. Trabajo también muy importante: PHILIPPEN, J. L. M., «Les béguines et l'héréise albigeoise» en Annales de l'Académie Royale d'Archéologie de Belgique. 75. 1925. pp. 233-246. 
El espíritu renovador de la reforma gregoriana influyó en gran manera al nacimiento de las beguinas y de ciertos grupos de hombres y mujeres que practicaban una vida retirada de piedad y de pureza evangélica ${ }^{67}$. Se ha justificado este aumento de espiritualidad femenina por la numerosas viudas de los cruzados, aunque esta teoría no es admitida en la actualidad por diversos especialistas. Estos movimientos laicos fueron rechazados por ciertos sectores de la Iglesia, pero, en contraposición, gozaron de la protección de poderosos señores. Las beguinas serán protegidas por Luis IX de Francia y por los condes de Flandes, Juan y Margarita. Clemente V condenó el movimiento en el Concilio de Vienne en $1311^{68}$, mientras que lo apoyó y restauró Juan XXII, separando las que permanecieron en la ortodoxia y aquéllas que, por contactos con diversas herejías, se habían alejado de la verdadera doctrina católica ${ }^{69}$.

Conviene avanzar un concepto que es fundamental para no confundir diversas tendencias espirituales acuñadas con el mismo nombre. Los espirituales, beguinos y beguinas de Cataluña, Valencia, Languedoc y Provenza sólo tenían el nombre común con los beguinos y beguinas de la Europa septentrional, y su evolución histórica será totalmente diferente. Mientras que los espirituales de estas regiones y los del norte de Italia, acusados de sostener doctrinas heterodoxas, serán eliminados durante el pontificado de Juan XXII por la bula Cum inter nonnulos (1325), los beguinos y beguinas del resto de Europa, principalmente las comunidades de mujeres de Flandes, continuarán una trayectoria ortodoxa hasta nuestros días.

Algunas de estas beguinas llegaron a ser mujeres célebres por motivos diversos: Matilde de Magdeburgo, Beatriz de Nazaret, Hadewijch de Amberes, Margarita Porete... Dos figuras insignes de este movimiento beguino fueron Marie d'Oignies (1176-1213), asceta, mística y profetisa en su ermitage sur la Sambre, cerca de Namur, y Douceline de Digne, mística auténtica, que nació en 1214

67. Esta reforma fue esencialmente la obra de varios pontífices: León IX, Gregorio VII, Nicolás II, Urbano II, Pascual II, Étienne IX, Víctor II, Honorio II, papas o antipapas, y de un grupo de prelados. La reforma gregoriana atacó a tres males importantes: las costumbres y moral del clero, la concesión de beneficios y la autoridad del pontífice romano en el gobierno de la Iglesia.

68. En el Concilio de Viena del Delfinado (16 de octubre de 1311) convocado por el papa Clemente V, principalmente para tratar de los templarios, también se abordaron algunas cuestiones teológicas derivadas de la perpetua discordia entre los dos grupos de la Orden franciscana. Estas cuestiones giraron en torno de Pedro Juan Olivi y de su célebre opinión, según la cual, Jesús murió en la cruz por la herida de la lanza del centurión. La constitución Fidei catholicae fundamento, leída en la sesión del día 6 de mayo de1312, proclamaba que el costado de Cristo no fue abierto hasta después de su muerte.

69. Redondo, V., «Los movimientos femeninos en tiempos de Francisco de Asís» en Estudios Franciscanos. Vol. 93. Mayo-diciembre. Núms. 404-405. Barcelona. 1992. pp. 197-239. Cita de las pp. 222-223. Véase también: SAntonja, P., «Arnau de Vilanova i la seua relació amb els beguins i espirituals» en Estudios Franciscanos. Vol. 92. Enero-agosto. Núms.: 400-401. Barcelona. 1991. pp.: 25-53. 
como para recoger la antorcha de esta espiritualidad femenina. Marie d'Oignies nació en Nivelles (Brabant), perteneciendo a una rica familia. Se casó a los catorce años y convenció a su esposo a vivir como hermanos en la pobreza personal. Sirvieron a los marginados de la leprosería cercana de Willambroux durante tres años. Luego, María quiso vivir la pobreza total y se instaló en una celda cerca del priorato de canónigos regulares de Oignies ${ }^{70}$. Conocemos mucho de Douceline de Digne a través de Li vida de la benaurada sancta Doucelina mayre de las donnas de Robaut ${ }^{71}$, escrita por una de sus compañeras, Felipa de Porcelet, mujer laica como ella, que se ha considerado una obra maestra de la hagiografía escrita en lengua d'Oc. La lectura de esta obra nos informa sobre las características del béguinage meridional que perduró hasta el siglo XV en Hyères y en Marsella $^{72}$. Douceline contó siempre con el valioso apoyo de su hermano Hugues de Digne, franciscano y très ardent predicateur de la verité de Christ. Tanto éste como Douceline recibieron la influencia de Joaquín de Fiore. No es nada raro, por tanto, que se le atribuyera el don de la profecía (être habité par l'esprit de prophétie), resultado de su veneración por el visionario calabrés. Desde muy pequeña Douceline mostró gran disposición para la contemplación y pronto se dedicó al servicio de los pobres. Bajo sus vestidos llevaba un cilicio de cuero y otras marcas de mortificación torturaban su cuerpo ${ }^{73}$. Aunque las beguinas no hacían tradicionalmente voto de pobreza, Douceline, por amor a la Virgen, quiso ser pobre como ella, haciendo voto de pobreza. Como ocurrió más tarde, con otras monjas y beatas visionarias, esta carismática profetisa fue consultada por Charles d'Anjou (1227-1285), a quien le predijo, como así ocurrió, que sufriría muchas derrotas. Douceline fue una precursora de las mujeres místicas del siglo XIV que tuvieron gran ascendencia en los medios políticos de su tiempo ${ }^{74}$.

En el siglo XVI se produjo una gran eclosión de audaces beatas y monjas milagreras y visionarias, que fueron perseguidas y procesadas por el Tribunal de

70. Redondo, V., «Los movimientos femeninos en tiempos de Francisco de Asís». op. cit. pp.: 223. Marie d'Oignies era una mujer instruida sobre las Sagradas Escrituras y, en su lengua vulgar, explicaba los dogmas de fe a sus oyentes.

71. Sobre Douceline de Digne, véase: Brunel-Lobrichon, G., «Existe-t-il un christianisme méridiobal? L'exemple de Douceline: le Béguinage provençal» en Heresis, Revue Semestrielle d'Hérésiologie Médiévale, décembre 88. CNEC / Centre René Nelli. No: 11. Villegly. 1988. pp.: 41-51. Véase también: Carozzi, C., «Une béguine joachimite: Douceline, soeur d'Hugues de Digne» en Cahiers de Fanjeaux, 10. 1974. pp. 169-201. El mismo autor: «Douceline et les autres», en Cahiers de Fanjeaux, 11. 1986. pp. 251-267.

72. Brunel-Lobrichon, G., «Existe-t-il un christianisme méridiobal? L'exemple de Douceline: le Béguinage provençal». op. cit. p. 41 b.

73. Ibidem, p. 43 a, b. Marie d'Oignies, en el norte, también se sometió a severas mortificaciones, muriendo a los treinta y seis años, destruida por los ayunos...

74. Ibidem, p. 51 a. 
Santo Oficio. Ya a principios del siglo (1509-1511) se vio la causa contra la beata de Piedrahita, hija de un labrador de Piedrahita, obispado de Ávila. Educada en Salamanca, se dedicó tanto a la oración y a las mortificaciones del ayuno y otras que, exaltada su imaginación por las debilidades, cayó en la ilusión. Decía ver a Jesús y a María. Vestía hábito de beata o religiosa de la orden tercera de Santo Domingo; se titulaba esposa de Jesucristo, y se consideraba acompañada siempre por la Virgen María ${ }^{75}$. Sorprendió con sus arrebatos místicos y sus ayunos prolongados. A pesar de las sátiras despiadadas que escribieron contra ella algunos religiosos contemporáneos, lo cierto es que los delegados apostólicos que juzgaron su causa no vieron desviaciones heréticas en su espiritualidad. Permanecía en éxtasis largas horas, sin mover ni pie ni mano, y se anunciaba como esposa del Salvador. Los más la tenían por santa; algunos la llamaban ilusa, calificativo que, al igual que iludente, aparece con frecuencia en los manuscritos de los procesos inqisitoriales ${ }^{76}$. La examinaron muchos teólogos, y hubo entre ellos diversos pareceres sin atreverse a decidir si el espíritu que hablaba en aquella mujer era celeste o diábolico. La Inquisición le formó proceso por sospechas de iluminismo (alumbrada), pero, como no resultaba error claro y la beata tenía altos protectores la causa quedó indecisa ${ }^{77}$. El rey y el Inquisidor General estaban a favor de la beata y la suponían asistida del espíritu divino; los comisionados del papa no hallaron qué reprender en su conducta de palabras y obras, y dejaron a la disposición de la Providencia divina el momento de manifestar si el espíritu que dominaba a la beata era de Dios o del diablo ${ }^{78}$.

Hubo otras beatas y mojas milagreras y visionarias durante el siglo XVI, como Magdalena de la Cruz, Francisca Hernández, Francisca de Ávila, alias de los apóstoles, Sor María de la Visitación, la Monja de Lisboa..., pero éstas serán motivo de otro trabajo.

75. Llorente, J. A., Historia crítica de la Inquisición en España. 4 vol.s. Libros Hiperión. Colección dirigida por Jesús Munárriz. Ed. Hiperión. Pozuelo de Alarcón. Madrid. 1980. p. 273 del vol. I. Puesto que siempre iba acompañada por la Virgen María, cuando tenía que pasar por una puerta estrecha se detenía como para dar paso a la otra persona.

76. Iluso/a: engañado, seducido... este apelativo se daba a los que se creían inspirados por la divinidad. Iludente: así se llamaba a los que simulaban visiones, apariciones...

77. Menéndez Pelayo, M., Historia de los heterodoxos españoles. Tomo II, y último, BAC. Madrid. 1978. pp.: 149-150. Véase también: Beltrán de Heredia, V., O.P., «La beata de Piedrahita no fue alumbrada» en Ciencia Tomista, 61. 1942. pp. 294-311 y LlorCA, B., S. J., «La beata de Piedrahita, ¿fue o no fue alumbrada?» en Manresa, 14. Mayo, 1942. pp. 42-62. Septiembre, 1944. pp. 275-285. Del mismo autor: Die spanische Inquisition und die «Alumbrados»(1509- 1667), nach den originalakten in Madrid und anderen Archiven. Ferd. Dümmlers Verlag. Berlin und Bonn. 1933. pp. 6-14: Die Beata von Piedrahita.

78. Llorente, J. A., Historia crítica de la Inquisición en España. Tomo I. op. cit. p. 274. 